\title{
Metoclopramide-OROS Dispersible Tablets Optimized Formula Bioavailability Study
}

\author{
Samran Samran ${ }^{1 *}$, Hari Ronaldo Tanjung ${ }^{2}$ \\ ${ }^{1}$ Department of Pharmacy, STIKes Indah Medan, Medan, Indonesia; ${ }^{2}$ Department of Pharmacology, Faculty of Pharmacy, \\ Universitas Sumatera Utara, Indonesia
}

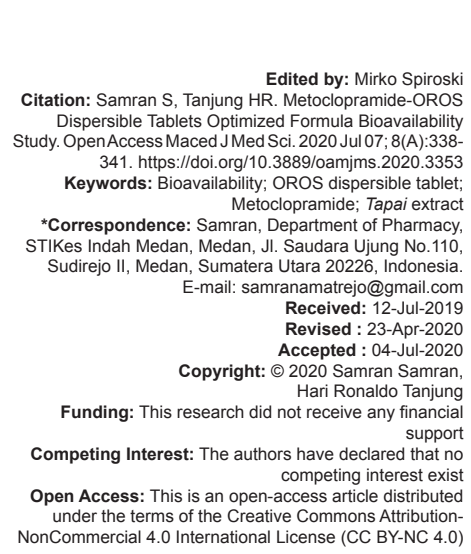

\section{Introduction}

OROS dispersible tablets (ODTs) are a solid dosage form containing active ingredients of drugs and destroyed quickly within a few seconds when placed on the surface of the tongue [1], [2], [3]. ODTs have several advantages such as disintegrate rapidly on the tongue, usually only takes a few seconds without the need for water to swallow, providing rapid early onset of action, and significantly increase the bioavailability of the conventional dosage form [4], [5], [6]. The drug administration problem occurred by the geriatric or pediatrics in consume the solid dosage form/tablets could be resolve by ODT preparation [7], [8].

Metoclopramide administered to the patients who have travel sickness and may have no water supply at the time to take the medicine and it was chosen as a model drug in this study. The ODTmetoclopramide formulas were design by simplex lattice design model with a three components mixture of excipients (solid tapai extract, corn starch, and Avicel). The optimum formula of ODT-metoclopramide
(FCL-6) consists of solid tapai extract $(27.038 \mathrm{mg})$, corn starch (27.407 mg), and Avicel (53.555 mg), metoclopramide $\mathrm{HCl}(10.00 \mathrm{mg}), \mathrm{LH}-11(22.50 \mathrm{mg})$, aspartame $(5.00 \mathrm{mg})$, talcum BP $(3.00 \mathrm{mg})$, and $\mathrm{Mg}$ stearate $(1.50 \mathrm{mg})$ [9].

Bioavailability and bioequivalence studies required by regulations to ensure therapeutic equivalence between a pharmaceutically equivalent test product and a reference product. Several in vivo and in vitro methods used to measure product quality. Bioequivalence documentation was also needed to establish links between early and late clinical trial formulations, formulations used in clinical trials and stability studies, clinical trial formulations and to be marketed drug products, and other comparisons, as appropriate. In each comparison, the new formulation or new method of manufactured shall be the test product and the prior formulation (or respective method of manufacture) shall be the reference product [10], [11]. This study aims to study the bioavailability performance between the optimum formula of ODT-metoclopramide dosage forms (FCL-6) and the Primperan $^{\circledR}$ as the reference product. 


\section{Materials and Methods}

Materials that used in this study were metoclopramide (PT. First Medifarma), acetic acid (glacial), acetonitrile, methanol, aqua pro-injection, metoclopramide $\mathrm{HCl} \mathrm{BP}$ (PT. Kairos Tritunggal), trichloroacetic acid (TCA) $20 \%$, and heparin. Highperformance liquid chromatography (HPLC) (Agilent 1120 Compact LC), Colom ODS C-18, solvent container (Oberol), vial (Agilent), animal box, vacuum pump (Gast DO), sonicator (Branson), paper membrane filter cellulose nitrate $0.45 \mu \mathrm{m}$ (Whatman), paper membrane filter nylon $0.45 \mu \mathrm{m}$ (Whatman), PTFE $02 \mu \mathrm{m}$ (Whatman), Primperan ${ }^{\circledR}$ (PT. SOHO), Avicel PH 102, Solid tapai extract, Corn starch, LH-11, and Mg stearate were used.

The in vivo test was done by cross-over design method [12] using six rabbits. The rabbits used in this study were male, aged 6 months old and weighed $1.5-2.0 \mathrm{~kg}$. The rabbits were acclimatized for 2 weeks to adapt with the environment. Administration of metoclopramide in rabbit by this method is shown in Table 1. The conventional Primperan ${ }^{\circledR}$ tablets were used as a positive control in evaluating the FCL-6 bioavailability performance.

The rabbit fasted for approximately $12 \mathrm{~h}$ and administered with the optimized ODT-metoclopramide (FCL-6) and Primperan ${ }^{\circledR}$ on an oral basis which is shown in Table 1 . The rabbit's blood was taken through a marginal vein at certain intervals of time: $10,20,30$, $45,60,90,120,180,300$, and 420 min using a $1.0 \mathrm{~mL}$ syringe. The needle was rinsed first with heparin. The rabbit blood then inserted into the centrifuge tube that has two drops of heparin. Then, $1.0 \mathrm{~mL}$ of TCA $20 \%$ was added to the tube and homogenized by vortex instrument. The tube centrifuged at $3000 \mathrm{rpm}$ for $10 \mathrm{~min}$ then the supernatant filtered using a $0.2 \mu \mathrm{m}$ PTFE filter membrane and measured using a HPLC instrument by injecting $10 \mu \mathrm{L}$ of supernatant.

Bioavailability test of metoclopramide in plasma of rabbit blood was measured by next procedure: The rabbits were given the oral medications in accordance with the bioequivalence test design that is shown in Table 2. At intervals, 10, 20, 30, 45, 90, 120, 180, 300, and $420 \mathrm{~min}$, the rabbits blood were taken with the help of a $1.0 \mathrm{~mL}$ syringe that has been rinsed with heparin, transferred to a centrifuge tube containing two drops of heparin and added TCA $20 \% 1 \mathrm{~mL}$, centrifuged at $3000 \mathrm{rpm}$ for $10 \mathrm{~min}$ then take the supernatant. The

Table 1: Administration of FCL-6 and Primperan ${ }^{\circledR}$ in rabbits

\begin{tabular}{lllll}
\hline Treatment I & & & Treatment II & \\
\cline { 5 - 5 } Rabbit & Drug & & Rabbit & Drug \\
\hline 1 & A & Rest for 1 week & 1 & B \\
2 & A & 2 & B \\
3 & A & 3 & B \\
4 & B & 4 & A \\
5 & B & 5 & A \\
6 & B & 6 & A \\
\hline A $=$ FCL-6, B $=$ Tablet Primperan & & &
\end{tabular}

supernatant filtered with PTFE $0.2 \mu \mathrm{m}$ filter membrane then determined the concentration of metoclopramide using HPLC instrument. Data analysis has been carried out using Microsoft Excel to calculate the value of $t_{\max }, C_{\max }$, and area under curve (AUC). The AUC concentration was determined by trapezoidal formula. The statistical comparison of $\mathrm{C}_{\max }$ and $\mathrm{AUC}$ values between the two formulas was analyzed using the independent sample t-test method.

\section{Results}

The study result revealed an average maximum peak time (tmax) was $60 \mathrm{~min}$. This means that the maximum concentration was reached at minute 60 . The relationship between plasma drug concentration $(C)$ and cumulative percentage of timeoff drugs ( $\mathrm{t}$ ) of optimized ODT-metoclopramide (FCL-6) and Primperan ${ }^{\circledR}$ revealed in Figure 1.

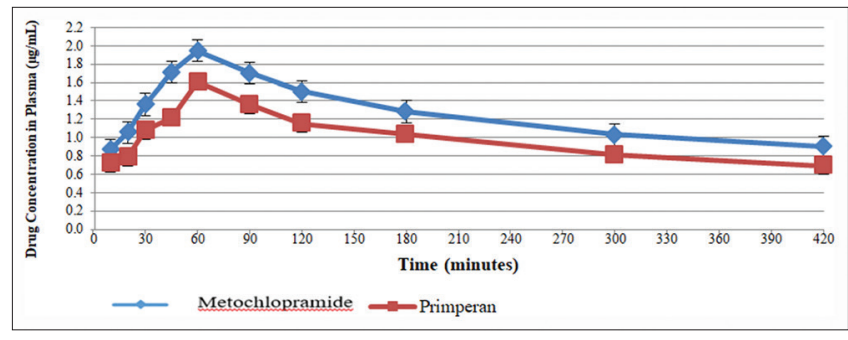

Figure 1: The relationship of mean drug concentrations versus times in rabbits plasma

Based on the data in Figure 1, it can be determined tmax, $\mathrm{C}_{\max }$, and AUC. The results revealed in Table 2. It showed that the maximum concentration $\left(\mathrm{C}_{\max } \mathrm{C}_{\max }\right)$ of FCL-6 $(1.94456 \pm 0.1340 \mu \mathrm{g} / \mathrm{mL})$ was larger than Primperan tablets $(1.61240 \pm 0.1843 \mu \mathrm{g} / \mathrm{mL})$. This means that FCL- 6 was absorbed faster than Primperan $^{\circledR}$.

Table 2: The values of $\mathrm{t}_{\text {max }}, \mathrm{C}_{\text {max }}$, and AUC

\begin{tabular}{|c|c|c|c|}
\hline \multirow[t]{2}{*}{ Formula } & \multicolumn{3}{|c|}{ Means \pm SD } \\
\hline & $\mathrm{t}_{\max }(\min )$ & $\mathrm{C}_{\max }(\mu \mathrm{g} / \mathrm{mL})$ & AUC $(\mu \mathrm{g} / \mathrm{mL} . \min )$ \\
\hline$\overline{F C L-6}$ & 60 & $1.95 \pm 0.1340$ & $1118.20 \pm 149.99$ \\
\hline Primperan $®$ & 60 & $1.61 \pm 0.1843$ & $759.26 \pm 108.46$ \\
\hline
\end{tabular}

The AUC calculated by the trapezoidal formula (against the amount of the drug absorbed in the blood). AUC of FCL-6 (1118.20 $\pm 149.99 \mu \mathrm{g} / \mathrm{mL}$ min) was larger compared with Primperan ${ }^{\circledR}$ tablets (854.45 $\pm 251.7 \mu \mathrm{g} / \mathrm{mL} \min )$. This is because STP has a highly soluble nature in water and Avicel and CS have disintegrating agent properties so that FCL-6 was more rapidly dissolved and absorbed. As the result, the amount of the drug absorbed in the blood (AUC) was larger than Primperan ${ }^{\circledR}$ tablets [13].

The bioequivalence data between optimized ODT-metoclopramide and Primperan $^{\circledR}$ revealed in Table 3. 
Table 3 shows that the Relative Bio-Availability (RBA) was larger than 1.25 and larger than $0.8, t_{\max }$ and $C_{\max }$ were in range. Based on these results, the two preparations were claimed to be not bioequivalence. This condition was occur because the optimized ODTmetoclopramide contains water-soluble STP, Avicel and CS have disintegrator properties so that this optimized ODT-metoclopramide dissolves and absorbed faster than Primperan ${ }^{\circledR}$ tablets. As the result, the $C_{\text {max }}$ and the concentration of the drug absorbed in the blood (AUC) of ODT-metoclopramide (FCL-6) were larger than Primperan ${ }^{\circledR}$ tablets.

Table 3: Optimized ODT-metoclopramide and Primperan ${ }^{\circledR}$ bioequivalence data

\begin{tabular}{lll}
\hline Parameters & Comparing value A/B & Range parameters \\
\hline $\mathrm{AUC}$ & 1.47 & $0.8<\mathrm{AUC}(\mathrm{A} / \mathrm{B})<1.25$ \\
$\mathrm{t}_{\max }$ & 1 & $0.8<\mathrm{t}_{\max }(\mathrm{A} / \mathrm{B})<1.25$ \\
$\mathrm{C}_{\max }$ & 1.21 & $0.8<\mathrm{C}_{\max }(\mathrm{A} / \mathrm{B})<1.25$ \\
\hline $\mathrm{A}=\mathrm{FCL}-6, \mathrm{~B}=$ Primperan $\otimes$. & AUC:
\end{tabular}

Results of the FCL-6 and Primperan $^{\circledR}$ parameters of bioavailability statistically analysis are shown in Table 4.

Table 4: Result of statistical data analysis of the FCL-6 and Primperan $^{\circledR}$ test

\begin{tabular}{llll}
\hline Treatments & No. of treatment & Means \pm SD & $p$ \\
\hline $\mathrm{C}_{\max }$ FCL-6 & 6 & $1.94456 \pm 0.1340$ & 0.005 \\
$\mathrm{C}_{\max }$ Primperan & & $1.61240 \pm 0.1843$ & \\
AUC FCL-6 & 6 & $1118.20 \pm 149.99$ & 0.001 \\
AUC Primperan & & $854.45 \pm 251.7$ & \\
\hline AUC: Area under curve & & &
\end{tabular}

Statistical data of the optimized and Primperan ${ }^{\circledR}$ ODT-metoclopramide testing with t-test in Table 4 showed that the $\mathrm{C}_{\max }$ and AUC significance values were $<0.05$ $(p<0.05)$ and this means that at a 95\% confidence level, there was a significant difference between $\mathrm{C}_{\max }$ and AUC value of the two drugs compared.

\section{Discussion}

The study was determined pharmacokinetic parameters of the optimized ODT-metoclopramide formula, FCL-6, from the observed plasma concentration time profiles. The marketed preparation through oral administration, Primperan ${ }^{\circledR}$, was selected for reference product since these preparations are already clinically proven. From bioavailability studies, it can be concluded that FCL-6 was capable to deliver the drug in systemic circulation since the RBA by ODT formulation with tapai extract was found to be $147 \%$. The comparison of $C_{\text {max }}$ and $A \cup C$ value also showed the significantly differences between FCL- 6 and Primperan ${ }^{\circledR}$ where FCL- 6 showed the superiority to Primperan ${ }^{\circledR}$. These facts are in similar with the findings revealed by Shyamala and Narmada [4], Pawar and Junagade [5], and Shah and Mehta [6] that ODT formulation was capable to significantly increase the bioavailability of the conventional dosage form.

The AUC value of FCL-6 (1118.20 \pm $149.99 \mu \mathrm{g} / \mathrm{mL}$. $\min )$ showed the higher value when compared with the AUC value $(2716 \pm 4.62$ ng.h/mL) from Galgatte and Chaudhari [14] that study the bioavailability of mucoadhesive thermo reversible in situ gel-metoclopramide that administered nasally to New Zealand rabbits. Meanwhile, another study by Ward et al. [15] stated that the intranasal route did not allow rapid absorption of the metoclopramide and was not associated with greater bioavailability than the oral route. Therefore, the order of bioavailability is i.v. > ODT $>$ nasal [14], [15], [16].

The RBA study also referred as a pilot pharmacokinetics study was used by the drug development sponsor to assess potential in vivo performance differences between dosage forms. The data obtained from the RBA study allow the sponsor to move forward in clinical development with a new dosage form [17], [18], [19], [20]. The RBA of FCL-6 $(147 \%)$ also showed the higher value compare with the RBA value of metoclopramide nasal spray dosage form $(62.3 \%)$ that mentioned by Li et al. study [21]. It revealed that the optimized ODT-metoclopramide with tapai extract (FCL-6) has the ability to increased bioavailability of metoclopramide.

\section{Conclusion}

It can be concluded that the optimized formula of ODT-metoclopramide (FCL-6) has a better characteristic of $\mathrm{C}_{\max }$ and AUC concentration compared with Primperan ${ }^{\circledR}$. The optimized ODT-metoclopramide with tapai extract dosage forms (FCL-6) was found to be promising to improved bioavailability of metoclopramide.

\section{Acknowledgment}

The authors acknowledge that the research supported by STIKes Indah Medan, Medan, Indonesia.

\section{References}

1. Hirani JJ, Dhaval AR, Kantilal RV. Orally disintegrating tablets: A review. Trop J Pharm Res. 2009;8(2):161-72.

2. Laddha UD, Zilpelwar RV. Mouth dissolving tablet: A nove approach for better patient compliance. Int J PharmTech Res. 2015;8(6):56-64.

3. Ramu B, Ramakrishna N, Sathish M, Anoosha D. Formulation of telmisartan $\mathrm{HCl}$ fast disintegrating tablets by sublimation method. Int J PharmTech Res. 2015;8(3):330-9.

4. Shyamala B, Narmada GY. Rapid dissolving tablets: A novel dosage form. Indian Pharm. 2002;13(8):9-12. 
5. Pawar SV, Junagade MS. Formulation and evaluation of mouth dissolving film of risperidone. Int $\mathrm{J}$ PharmTech Res. 2015;8(6):218-30.

6. Shah KR, Mehta TA. Design and development of fast disintegrating dosage form of taste masked lornoxicam. Int $\mathrm{J}$ PharmTech Res. 2015;8(4):581-94.

7. Samran, Karsono. Methochlopramide orally disintegrating tablet formulation using co-processed excipient of solid tapai extract and corn starch. Int J PharmTech Res. 2015;8(9):91-8.

8. Das IJ, Deepthi R, Rajashekar Y, Samal HB. Design and characterization of glimepiride fast dissolving tablets. Int $\mathrm{J}$ PharmTech Res. 2015;8(7):1-11.

9. Samran, Karsono, Simanjuntak MT, Silalahi J. Optimization of metoclopramide-orally disintegrating tablet using solid tape extract and corn starch. Indones J Pharm Sci. 2013;11(1):21.

10. CADTH; 2012. What are Bioavailability and Bioequivalence? Available from: https://www.cadth.ca/What_Are_Bioavailability_ and_Bioequivalence_e.pdf. [Last accessed on 2020 Apr 20].

11. Ministry of Health and Family Welfare of India. Guideline for Bioavailability and Bioequivalence Studies; 2005. Available from: http://www.cdsco.nic.in/html/guidelines.pdf. [Last accessed on 2020 Apr 20].

12. Hanafiah KA. Experiments Design: Theory and Application. $3^{\text {rd }}$ ed. Jakarta: Raja Grafindo Persad; 1995. p. 19-20, 34-42.

13. Bhowmik D, Chiranjib $B$, Krishnakanth $P$, Margret $R$. Fast dissolving tablet: An overview. J Chem Pharm Res. 2009;1(1):1-5.

14. Galgatte UC, Chaudhari PD. Development of metoclopramide hydrochloride in situ gel: Nasal delivery and pharmacokinetics in New Zealand rabbits. Asian J Pharm Clin Res. 2019;12(4):280-5. https://doi.org/10.22159/ajpcr.2019.v12i4.31779

15. Ward MJ, Buss DC, Ellershaw J, Nash A, Routledge PA. Bioavailability of intranasal metoclopramide. Br J Clin Pharmacol. 1989;28(5):616-8. https://doi.org/10.1111/j.1365-2125.1989.

\section{tb03552.x}

PMid:2590616

16. Duchateau ZJ, Albers W, Merkus M. Nasal absorption of alprenolol and metoprolol. Int J Pharm. 1996;34:131-6.

17. Aktham A, Sperry DC, Bhattachar S, Lobo E, Ding X, Rose JP. Relative bioavailability risk assessment: A systematic approach to assessing in vivo risk associated with CM\&C-related changes. J Pharm Sci. 2019;108(1):8-17. https://doi.org/10.1016/j. xphs.2018.07.012

PMid:30053554

18. U.S. Food and Drug Administration. Guidance for Industry: Bioavailability and Bioequivalence Studies For Orally Administered Drug Products General Considerations. Silver Spring, MD: U.S. Food and Drug Administration; 2003. Available from: https://www.ipqpubs.com/wp-content/uploads/2014/04/ BABEOld.pdf. [Last accessed on 2020 Apr 21].

19. European Medicines Agency. Guideline on the Investigation of Bioequivalence. London, UK: European Medicines Agency; 2010. Available from: http://www.ema.europa.eu/docs/en_GB/ document_library/Scientific_guideline/2010/01/WC500070039. pdf. [Last accessed on 2020 Apr 21].

20. Pharmaceutical and Medical Devices Agency. Guideline for Bioequivalence Studies of Generic Products. Tokyo, Japan: Pharmaceutical and Medical Devices Agency; 2012. Available from: http://www.nihs.go.jp/drug/be-guide(e)/Generic/GL-E_120229_ BE_rev140409.pdf. [Last accessed on 2020 Apr 21].

21. Li Y, Fan X, Li W, Yang P, Zhang H, Tang D, et al. Metoclopramide nasal spray in vitro evaluation and in vivo pharmacokinetic studies in dogs. Pharm Dev Technol. 2018;23(3):275-81. https:// doi.org/10.1080/10837450.2017.1316734

PMid:28379057 